\title{
Uma Investigação sobre as Forças, Fraquezas, Oportunidades e Ameaças na Dimensão de Negócios para Desenvolvedores em Ecossistemas de Software Móvel An Investigation of the Strengths, Weaknesses, Opportunities and Threats in the Business Dimension for Develpers in Mobile Software Ecosystems
}

\section{Caio Steglich ${ }^{1}$, Rodrigo Santos ${ }^{2}$, Sabrina Marczak ${ }^{1}$, Marcelo Perin ${ }^{3}$, Luiz Henrique} Mosmann $^{1}$, Luiz Pedro Guerra ${ }^{1}$, Cleidson de Souza ${ }^{4}$, Fernando Figueira Filho

${ }^{1}$ Escola Politécnica Pontifícia Universidade Católica do Rio Grande do Sul (PUCRS)

Porto Alegre - Brazil

${ }^{2}$ Programa de Pós-Graduação em Informática Universidade Federal do Estado do Rio de Janeiro (UNIRIO)

Rio de Janeiro - Brasil

${ }^{3}$ Escola de Administração de Empresas de São Paulo Fundação Getúlio Vargas (FGV)

São Paulo - Brasil

${ }^{4}$ Faculdade de Computação Universidade Federal do Pará (UFPA) Belém - Brasil

${ }^{5}$ Departamento de Informática e Matemática Aplicada Universidade Federal do Rio Grande do Norte (UFRN) Natal - Brasil

\footnotetext{
\{caio.borges, luiz.mosmann, luiz.guerra\}eacad.pucrs.br, rps@uniriotec.br, sabrina.marczak@pucrs.br, marcelo.perin@fgv.br, cleidson.desouzalacm.org, fernandoddimap.ufrn.br
}

\begin{abstract}
Mobile Software Ecosystems (MSECO) are those in which developers interact to create mobile applications to address the users' demands. In this study, we aimed to identify how the business dimension can affect the decision on the participation of an ecosystem or in developers' career. Consequently, we conducted the following studies: i) A Systematic Mapping Study to identify those business factors; ii) a Field Study to verify how such factors influence the developers' decisions regarding their participation in an MSECO; and iii) another Field Study with evangelists to identify the strengths, weaknesses, opportunities
\end{abstract} Vol(num), 74-97. DOI. 10.5753/isys.2021.2015. 
and threats that the ecosystem business dimension brings to developers. As a result, 12 factors have been identified. Such factors can drive developers on the understading of how each factor can affect developers' participation as well as the biggest strenghts, weaknesses, opportunities and threats in the business dimension of an MSECO.

Keywords. Mobile Software Ecosystems, Business Factors, Empirical Studies

Resumo. Ecossistemas de software (ECOS) móvel são aqueles nos quais os desenvolvedores interagem para a criação de aplicações móveis a fim de atender aos usuários das plataformas relacionadas. Nesta pesquisa, buscou-se a identificação de como a dimensão de negócio pode impactar na decisão de participar de um ecossistema ou em sua carreira. Para isso, conduziu-se os seguintes estudos: i) um Mapeamento Sistemático da Literatura para identificação destes fatores de negócio; ii) um Estudo de Campo para verificação de como estes fatores influenciam as decisões dos desenvolvedores quanto à sua participação em um ECOS móvel; e iii) um novo Estudo de Campo com evangelistas para a identificação de forças, fraquezas, oportunidades e ameaças que a dimensão de negócio traz para os desenvolvedores. Como resultado, identificou-se 12 fatores. Estes fatores podem influenciar os desenvolvedores na compreensão de como cada um deles pode impactar a participação dos desenvolvedores, bem como as maiores forças, fraquezas, oportunidades e ameaças em um ECOS móvel.

Palavras-Chave. Ecossistemas de Software Móvel, Fatores de Negócio, Estudo Experimental

\section{Introdução}

Os Ecossistemas de Software (ECOS), que têm produzido soluções de software na atualidade, são formados por um conjunto interno e externo de desenvolvedores, uma comunidade de especialistas de domínio em serviço e uma comunidade de usuários, que trabalham em conjunto para ofertar soluções relevantes para satisfazer as necessidades desses usuários [Bosch e Bosch-Sijtsema 2010]. ECOS móvel são ecossistemas que atuam sobre o contexto móvel [Fontao et al. 2015], ou seja, aqueles que têm como objetivo a produção de aplicativos para dispositivos móveis (e.g. smartphones). Esta classe de ECOS possui dois grandes líderes de mercado, Google (Android) e Apple (iOS) [Mallinson 2015]. Pela importância que estes ECOS têm, torna-se fundamental o estudo sobre sua sustentabilidade, sendo esta baseada em dois pilares principais: i) adaptação a novas tecnologias, recursos e tendências; e ii) atração e manutenção de membros na comunidade do ECOS [Dhungana et al. 2010]. Portanto, pesquisas são necessárias para explorar estes dois pilares, a fim de assegurar tanto a participação de novos membros da comunidade como a manutenção daqueles que ela já possui. Neste contexto, o entendimento sobre a percepção do desenvolvedor quanto a fatores que podem influenciá-lo é fundamental para a sustentabilidade de um ECOS.

Alguns estudos apresentam fatores que poderiam levar um desenvolvedor a adotar um ECOS móvel [Koch e Kerschbaum 2014]. Contudo, é importante entender a im-

iSys: Revista Brasileira de Sistemas de Informação (iSys: Brazilian Journal of Information Systems) http://seer.unirio.br/index.php/isys/ 
portância e a influência que uma dimensão de um ecossistema pode ter sobre um desenvolvedor e como pode essa influência pode ser percebida pelos desenvolvedores ao longo do tempo, desde que ele/ela começou a sua participação até um dado momento. Portanto, alguns estudos são focados na adoção de um ECOS móvel [Koch e Kerschbaum 2014] e outros na permanência do desenvolvedor [Ryu et al. 2014]. Nesta pesquisa, busca-se identificar a opinião dos desenvolvedores nestes dois prismas.

O conceito de ECOS pode ser entendido em três dimensões: técnica, social e de negócio [Campbell e Ahmed 2010, Santos e Werner 2011]. Assim sendo, os pesquisadores envolvidos no presente trabalho investigaram, em estudos anteriores, como fatores sociais e fatores técnicos [Steglich et al. 2019a, Steglich et al. 2019b] poderiam influenciar os desenvolvedores a começarem ou se manterem participando de um ECOS móvel. Neste trabalho, temos como objetivo investigar o recorte dos fatores da dimensão de negócio e como podem influenciar os desenvolvedores de ECOS móvel. Destaca-se que este cenário tem contribuído para a transformação digital e para agregar mais complexidade ao desenvolvimento de sistemas de informação, notadamente evidenciando os aspectos sociais e de negócio em processos de tomada de decisão [Boscarioli et al. 2017].

Este artigo é uma versão estendida de um estudo anterior [Steglich et al. 2020], no qual fora relatado a condução de um mapeamento sistemático da literatura para identificar um conjunto de fatores, além de um estudo de campo com desenvolvedores de ECOS móvel, que contou com 20 respondentes, para entender como estes fatores influenciam os desenvolvedores a participarem ou continuarem participando de um ecossistema. Nesta versão estendida, buscou-se identificar de forma mais geral como características ou pontos da dimensão de negócios podem ser importantes para os desenvolvedores, que ocorreu por meio de um novo estudo de campo, utilizando-se de entrevistas estruturadas, de forma remota e não supervisionada com evangelistas de ECOS móvel, devido à pandemia da COVID-19. Este estudo foi formulado para entender as forças, fraquezas, oportunidades e ameaças presentes na dimensão de negócio de um ECOS móvel. Neste novo estudo, buscou-se realizar uma análise com evangelistas para se aprofundar na dimensão de negócio e suas características. As seções seguintes apresentam a fundamentação, os passos dos nossos estudos e os resultados obtidos, além da conclusão e trabalhos futuros.

\section{Fundamentação Teórica}

A definição adotada no presente estudo é a de Bosch e Bosch-Sijtsema [Bosch e Bosch-Sijtsema 2010], que definem que um ECOS consiste em uma plataforma de software, um conjunto interno e externo de desenvolvedores e uma comunidade de domínio que se dedica a compor soluções que satisfaçam às suas necessidades, conforme mencionado anteriormente. Em resumo, um ECOS engloba o processo de desenvolvimento de software nestas plataformas, de comercialização (por meio do mercado) e da comunidade que se engaja a colaborar com esses ECOS. Além disso, essa definição contempla as dimensões de um ECOS, conforme apresentado na Seção 2.1.

\subsection{Dimensões de um ECOS}

Um ECOS costuma contemplar três dimensões principais [Campbell e Ahmed 2010, Santos e Werner 2011], conforme explicado a seguir.

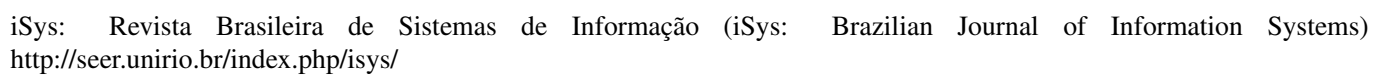


A dimensão técnica de um ECOS compreende as tecnologias utilizadas, os padrões e recursos de desenvolvimento, qualidade dos aplicativos, entre outros assuntos relacionado a tecnologias. Exemplos de elementos da dimensão técnica são as linguagens de programação permitidas pelo ECOS, os kits de desenvolvimento que facilitem a criação de aplicações ou aplicativos (apps) para um dado ecossistema e os ambientes de desenvolvimento.

Por sua vez, a dimensão social de um ECOS compreende as pessoas que fazem parte da comunidade de um ecossistema, com as suas relações entre si, funções ou ainda relações com o próprio ECOS. Exemplos de elementos da dimensão social são discussões realizadas em estudos que identificam a motivação do desenvolvedor e em estudos que investigam os sentimentos dos usuários quanto a algumas tecnologias.

Finalmente, a dimensão de negócio de um ECOS compreende as finanças, vendas de software, linhas de produção e oportunidade de emprego para desenvolvedores. Exemplos de elementos da dimensão de negócio são comparações entre a lucratividade de lojas de aplicativos de dois ECOS distintos e estudos sobre distribuição de uma mesma aplicação em diversos países diferentes. Ao longo deste estudo, são analisados os fatores de negócio que podem influenciar os desenvolvedores.

\subsection{Trabalhos Relacionados}

Diversos estudos sobre ECOS na área de Sistemas de Informação podem ser encontrados na literatura, o que traz a necessidade de estudos que explorem esta relação entre as duas áreas. Por exemplo, Abdalla et al. [Abdalla et al. 2018] propuseram uma plataforma baseada na reutilização de sistemas de recomendação, integrando diversos métodos de sistemas de recomendação.

Lima et al. [Lima et al. 2014] investigaram uma abordagem sócio-técnica e a interação entre atores e artefatos de um ECOS, analisando desta forma as dimensões técnica e social sob o prisma do uso de recursos sociais de um ecossistema. Meireles et al. [Meireles et al. 2019] investigaram a transparência em portais que pertençam aos ECOS por meio de um mapeamento sistemático, no qual buscaram identificar quais métodos, modelos e técnicas são mais utilizados para manter diferentes características que contribuem para transparência, sobretudo na dimensão de negócio.

Outro estudo correlato foi apresentado por Santos et al. [Santos et al. 2019], que identificaram e estudaram fatores humanos que poderiam ser relevantes a sistemas de informação por meio de um mapeamento da literatura, analisando-os na perspectiva de ECOS. Por fim, em um estudo anterior [Steglich et al. 2019a], os autores do presente artigo exploraram os fatores sociais que poderiam afetar os desenvolvedores de ECOS móvel, sendo esse publicado em uma conferência de alcance internacional.

\section{Metodologia da Pesquisa}

Esta pesquisa possui três questões de pesquisa:

(QP1) Quais são os fatores de negócio apresentados pela literatura que motivam o desenvolvedor a participar ou continuar participando de um ECOS móvel?

\footnotetext{
iSys: Revista Brasileira de Sistemas de Informação (iSys: Brazilian Journal of Information Systems) http://seer.unirio.br/index.php/isys/
} 


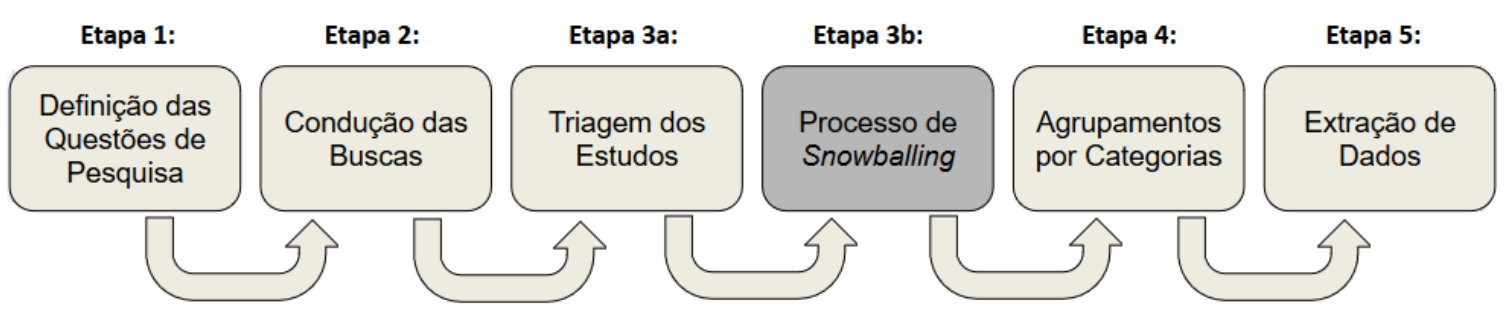

Figura 1. Processo de mapeamento sistemático da literatura utilizado.

(QP2) Como os desenvolvedores de ECOS móvel são influenciados por estes fatores de negócio identificados ao longo de sua experiência?

(QP3) Quais são as principais forças, fraquezas, oportunidades e ameaças na dimensão de negócios de um ECOS móvel para os desenvolvedores?

Esta pesquisa foi realizada em três estudos. O primeiro consistiu em um mapeamento sistemático da literatura visando identificar os fatores de negócio presentes na literatura que podem influenciar desenvolvedores de ECOS móvel. O segundo estudo consistiu em um estudo de campo no qual os desenvolvedores de tecnologias móveis foram convidados para explicar como cada um destes fatores os influenciaram tanto para adotarem como para se manterem participando de um ECOS móvel. O terceiro e novo estudo, apresentado especificamente neste artigo, consistiu de um estudo de campo com evangelistas para entender com maior profundidade a dimensão de negócio e seu impacto para os desenvolvedores.

\subsection{Mapeamento Sistemático de Literatura}

Para a condução do mapeamento sistemático da literatura (MSL), utilizou-se o processo apontado por Petersen et al. [Petersen et al. 2008]. O conjunto de estudos identificados por meio deste processo foram complementados utilizando a técnica de snowballing, apresentada por Wohlin [Wohlin 2014]. O processo adotado para este estudo está demonstrado na Figura 1, cujas etapas são: (1) Definição das questões de pesquisa, (2) Condução das buscas, (3a) Triagem dos estudos, (3b) Processo de snowballing, (4) Agrupamentos por categorias e (5) Extração dos dados.

\section{(1) Definição das Questões de Pesquisa}

Neste mapeamento, tomou-se como questão norteadora: "Quais estudos e fatores de negócio são apresentados pela literatura?”.

\section{(2) Condução das Buscas}

A etapa de Definição do Processo de Pesquisa de Petersen et al. [Petersen et al. 2008] envolve selecionar as bases nas quais foram buscados os estudos sobre ECOS móvel. As bibliotecas selecionadas foram as recomendadas por Kitchenham et al. [Kitchenham et al. 2009]: ACM Digital Library, IEEExplore Digital Libray, SCOPUS, Science Direct, Springer Database e Wiley Interscience. As strings de busca utilizadas tinham o seguinte formato, contendo os seguintes termos em seu título, resumo ou palavras-chave:

\footnotetext{
iSys: Revista Brasileira de Sistemas de Informação (iSys: Brazilian Journal of Information Systems) http://seer.unirio.br/index.php/isys/
} 
Title-Abstract-Keyword\{ MSECO OR [Mobile AND (Software Ecosystem OR SECO)] OR [smartphone AND (Software Ecosystem OR SECO)] \}

Este processo foi executado em junho de 2018 e obteve 532 estudos.

\section{(3a) Triagem dos Estudos}

A etapa de seleção de dados foi elaborada a partir da leitura do títulos, palavras-chave e resumos dos 532 estudos identificados e aplicação dos critérios de inclusão e de exclusão após a leitura de cada estudo.

Os critérios de inclusão foram:

(I1) Publicações sobre ECOS que apresentem características de software móvel em seus títulos, palavras-chave ou resumos.

(I2) Publicações que tratem ECOS móvel em seu título, palavras-chave ou resumo.

Os critérios de exclusão utilizados foram:

(E1) Estudos duplicados.

(E2) Estudos anteriores a 2007, pois a literatura sobre o tema teve o primeiro trabalho publicado em veículo científico em 2007 [Manikas e Hansen 2013].

(E3) Resumos de conferências.

(E4) Estudos que não estejam escritos em Português ou Inglês.

Ao término da aplicação destes critérios, 81 estudos foram selecionados.

\section{(3b) Processo de Snowballing}

O processo complementar de snowballing contou com dois subprocessos, sendo forward snowballing e backward snowballing, conforme segue:

- Forward: Dado o conjunto inicial (81 estudos), utilizou-se ferramentas como Google Scholar ${ }^{1}$ para identificar estudos que tenham citado os do conjunto inicial; em seguida, aplicou-se os critérios de seleção (3a), definindo assim um novo conjunto. Repetiuse o processo sobre o novo conjunto até que não surgissem novos estudos não classificados. Desta forma, identificou-se 28 novos estudos, sendo 26 encontrados no primeiro ciclo e 2 no segundo ciclo.

- Backward: Dado o conjunto inicial (81 estudos), utilizou-se as citações utilizadas nos mesmos e aplicou-se os critérios de seleção (3a), definindo assim um novo conjunto. Repetiu-se este processo sobre o novo conjunto até que não surgissem novos estudos não classificados. Desta forma, identificou-se 46 novos estudos, sendo 42 encontrados no primeiro ciclo e 4 no segundo ciclo.

Ao final do processo de snowballing, identificou-se $74(46+28)$ estudos novos. Após adicionados ao conjunto inicial (81 estudos), foram considerados 155 estudos iden-

\footnotetext{
${ }^{1}$ Google Scholar - https://scholar.google.com.br/ - Acessado em 19/06/2018 - 16:20

iSys: Revista Brasileira de Sistemas de Informação (iSys: Brazilian Journal of Information Systems) http://seer.unirio.br/index.php/isys/
} 
Tabela 1. Estudos selecionados.

\begin{tabular}{|c|c|c|}
\hline ID & Estudo & Citação \\
\hline E1 & Fontão, Dias-Neto e Santos (2017) & [Fontao et al. 2017] \\
\hline E2 & Sadi, Dai e Yu (2015) & [Sadi et al. 2015] \\
\hline E3 & Dobrica e Pietraru (2017) & [Dobrica e Pietraru 2017] \\
\hline $\mathrm{E} 4$ & Ryu, Kim e Kim (2014) & [Ryu et al. 2014] \\
\hline E5 & Kim, Kim e Lee (2016) & [Kim et al. 2016] \\
\hline E6 & Goldbach, Benlian e Buxmann (2017) & [Goldbach et al. 2017] \\
\hline E7 & Miranda et al. (2014) & [Miranda et al. 2014] \\
\hline E8 & Koch e Kerschbaum (2014) & [Koch e Kerschbaum 2014] \\
\hline E9 & Rieger e Majchrzak (2016) & [Rieger e Majchrzak 2016] \\
\hline E10 & Koch e Guceri-Ucar (2017) & [Koch e Guceri-Ucar 2017] \\
\hline E11 & Deniz e Kehoe (2013) & [Deniz e Kehoe 2013] \\
\hline E12 & Choi, Nam and Kim (2018) & [Choi et al. 2018] \\
\hline E13 & Ferreira (2016) & [Ferreira 2016] \\
\hline E14 & Choi, Nam e Kim (2017) & [Choi et al. 2017] \\
\hline E15 & Goldbach e Benlian (2015) & [Goldbach e Benlian 2015] \\
\hline
\end{tabular}

tificados sobre ECOS móvel.

\section{(4) Agrupamentos por Categorias}

De posse dos 155 estudos, o processo foi realizado por três pesquisadores e verificado por dois pesquisadores mais experientes na condução de mapeamentos sistemáticos. Além disso, foi realizada uma leitura mais aprofundada por parte dos pesquisadores em busca de estudos que trouxessem fatores que pudessem influenciar os desenvolvedores, sendo 15 estudos selecionados como mostra a Tabela 1. A extração dos fatores foi conduzida igualmente por três pesquisadores e conferida por dois pesquisadores mais experientes na condução de mapeamentos sistemáticos.

\section{(5) Extração dos Dados}

Após chegar ao conjunto de 15 estudos, realizou-se a extração dos fatores por meio da leitura detalhada de cada um dos estudos selecionados. Com isso, extraiu-se 167 fatores candidatos. Contudo, neste conjunto, ainda existiam fatores duplicados, similares ou que não se adequavam ao contexto de negócio (vide definição na Seção 2.1). Logo, o processo de análise descrito a seguir foi utilizado para chegar a um conjunto adequado que pudesse ser utilizado na etapa seguinte (Estudo de Campo), a fim de possibilitar a coleta da opinião dos desenvolvedores.

Para possibilitar o agrupamento e síntese dos fatores, foi utilizada uma estratégia conhecida como Card Sorting, apresentada por Spencer [Spencer 2009]. Após a seleção do estudo, fez-se a codificação dos textos de forma a identificar fatores e agrupá-los por similaridade. Mais especificamente, leu-se estudo por estudo, marcando trechos de texto 
Tabela 2. Exemplo do agrupamento realizado.

\begin{tabular}{|l|c|c|}
\hline ID & Fator & Citação \\
\hline 1 & Oportunidades no Mercado & [Koch e Kerschbaum 2014] \\
\hline \multicolumn{3}{|c|}{$\ldots$} \\
\hline 2 & Canais de Distribuição & [Sadi et al. 2015] \\
\hline \multicolumn{3}{|c|}{$\ldots$} \\
\hline 2 & Canais de Distribuição & [Ryu et al. 2014] \\
\hline \multicolumn{3}{|c|}{$\ldots$} \\
\hline 1 & Oportunidades no Mercado & [Dobrica e Pietraru 2017] \\
\hline \multicolumn{3}{|c|}{$\ldots$} \\
\hline
\end{tabular}

relevantes, registrando-os em uma planilha eletrônica junto à identificação de seu estudo fonte (vide Tabela 2). Uma vez concluída a leitura, releu-se os trechos separados e organizou-se pela proximidade de conteúdo e adicionando um nome de fator candidato. Esse técnica mais leve de codificação foi feita de maneira iterativa, até se estabilizar a categorização dos resultados, que foram revisados individualmente por 2 pesquisadores (um com 15 anos de atuação em Engenharia de Software e outro com 25 anos em Administração de Negócios, com ênfase em redes de conhecimento e ecossistemas). As discrepâncias foram resolvidas em uma reunião presencial entre os 3 pesquisadores.

Estes agrupamentos foram revisados por 3 pesquisadores experientes da área de Engenharia de Software (com mais de 15 anos de experiência). Os resultados discrepantes foram debatidos em grupo, gerando uma unanimidade em algum momento do debate. Ao final, chegou-se a 12 fatores de negócio que podem influenciar os desenvolvedores a colaborarem com um ECOS móvel.

\subsection{Estudo de Campo com Desenvolvedores}

Singer et al. [Singer et al. 2008] explicam que um estudo de campo visa investigar praticantes de alguma atividade e, por meio de alguma técnica, identificar de que forma eles lidam com a prática ou como resolvem problemas dentro de seus respectivos contextos.

Seguindo as recomendações de Singer et al. [Singer et al. 2008], desenvolvedores de software móvel com no mínimo um ano de experiência foram convidados a responder duas questões, quais sejam: i) "Como cada um dos fatores identificados na literatura impactou inicialmente o seu engajamento com um certo ECOS móvel?"e ii) "Como tem impactado atualmente?". Esses desenvolvedores foram convidados por conveniência usando a rede de contato dos pesquisadores e por disponibilidade no período de tempo que se tinha para realização do estudo. A caraterização do perfil dos 20 participantes que aceitaram participar está na Tabela 3, contendo o tempo de atuação dos desenvolvedores com tecnologias móveis e o porte das empresas que atuam, sendo: Pequena (até 100 funcionários), Média (de 101 a 1.000 funcionários) ou Grande (mais de 1.000 funcionários).

As entrevistas, gravadas e transcritas, duraram em média 25 minutos. Utilizouse o mesmo método de Card-Sorting relatado na Etapa 5 (Seção 3.1) para analisar as transcrições. Os resultados são apresentados na Seção 4. 
Tabela 3. Perfil dos desenvolvedores do primeiro estudo de campo.

\begin{tabular}{|c|c|c|c|c|}
\hline \multirow{2}{*}{ ID } & \multirow{2}{*}{ Porte da Empresa } & \multirow{2}{*}{ Tempo de Atuação } & \multicolumn{2}{|c|}{ ECOS } \\
\cline { 3 - 5 } & & Android & iOS \\
\hline D1 & Pequena & 5 anos & $\mathbf{X}$ & $\mathbf{X}$ \\
\hline D2 & Grande & 7 anos & $\mathbf{X}$ & $\mathbf{X}$ \\
\hline D3 & Média & 7 anos & $\mathbf{X}$ & \\
\hline D4 & Pequena & 9 anos & $\mathbf{X}$ & \\
\hline D5 & Pequena & 3 anos & $\mathbf{X}$ & $\mathbf{X}$ \\
\hline D6 & Pequena & 4 anos & $\mathbf{X}$ & \\
\hline D7 & Média & 6 anos & $\mathbf{X}$ & $\mathbf{X}$ \\
\hline D8 & Média & 3 anos & $\mathbf{X}$ & $\mathbf{X}$ \\
\hline D9 & Média & 3 anos & & $\mathbf{X}$ \\
\hline D10 & Média & 1 ano & $\mathbf{X}$ & $\mathbf{X}$ \\
\hline D11 & Média & 4 anos & & $\mathbf{X}$ \\
\hline D12 & Grande & 3 anos & $\mathbf{X}$ & $\mathbf{X}$ \\
\hline D13 & Pequena & 1 ano & $\mathbf{X}$ & \\
\hline D14 & Grande & 2 anos & $\mathbf{X}$ & $\mathbf{X}$ \\
\hline D15 & Pequena & 4 anos & & $\mathbf{X}$ \\
\hline D16 & Grande & 5 anos & $\mathbf{X}$ & $\mathbf{X}$ \\
\hline D17 & Pequena & 2 anos & & $\mathbf{X}$ \\
\hline D18 & Pequena & 2 anos & & $\mathbf{X}$ \\
\hline D19 & Pequena & 2 anos & $\mathbf{X}$ & \\
\hline D20 & Média & 2 anos & $\mathbf{X}$ & \\
\hline
\end{tabular}

\subsection{Estudo de Campo com Evangelistas de ECOS móvel}

Visando à identificação de possíveis forças, fraquezas, oportunidades ou ameaças sobre a dimensão de negócio para os desenvolvedores, optou-se pela realização de um novo Estudo de Campo de acordo com as recomendações de Singer et al. [Singer et al. 2008]. Contudo, as entrevistas para coleta de dados foram realizadas de forma estruturada, remota e não supervisionada, devido à pandemia de COVID-19. Os participantes receberam um questionário com o script e poderiam discorrer livremente sobre as questões discursivas. As questões elaboradas neste script de entrevista foram as seguintes:

- Qual é o seu nome?

- Qual é a sua atividade profissional atual?

- Qual é o porte/número de funcionários de sua empresa?

- Qual é a sua cidade/estado?

- Quantos anos você atua com computação?

- Quantos anos você atua como evangelista?

- Quais ecossistemas móveis você já colaborou?

- Dos 12 fatores identificados, qual importância você associa a cada um?

- Dos 12 fatores, quais deles você considera que configuram uma força, ou fraqueza, ou oportunidade, ou ameaça aos desenvolvedores de ECOS móvel? 
Tabela 4. Caracterização dos evangelistas.

\begin{tabular}{|c|c|c|l|}
\hline ID & $\begin{array}{c}\text { Porte da } \\
\text { Empresa }\end{array}$ & $\begin{array}{c}\text { Tempo de } \\
\text { Atuação }\end{array}$ & \multicolumn{1}{|c|}{ Ecossistemas que Participou } \\
\hline Ev1 & Grande & 1 ano & Windows Phone \\
\hline Ev2 & Médio & 10 anos & Android, Windows Phone, Nokia \\
\hline Ev3 & Médio & 15 anos & Android, iOS, Windows Phone \\
\hline Ev4 & Grande & 10 anos & Android, iOS, Symbian \\
\hline Ev5 & Grande & 6 anos & Android, iOS \\
\hline Ev6 & Grande & 5 anos & iOS \\
\hline Ev7 & Pequeno & 6 anos & iOS \\
\hline Ev8 & Grande & 7 anos & Android \\
\hline
\end{tabular}

- Em sua opinião, quais as maiores forças quanto à dimensão de negócio de um ECOS móvel?

- Em sua opinião, quais as maiores fraquezas quanto à dimensão de negócio de um ECOS móvel?

- Em sua opinião, quais as maiores oportunidades quanto à dimensão de negócio de um ECOS móvel?

- Em sua opinião, quais as maiores ameaças quanto à dimensão de negócio de um ECOS móvel?

- Gostaria de comentar algo sobre este estudo ou tópico desta pesquisa?

Esses evangelistas foram convidados por conveniência usando a rede de contato dos pesquisadores e por disponibilidade. Por definição, um evangelista é um desenvolvedor ou usuário com amplo conhecimento sobre um ecossistema, que eventualmente é contratado pela organização central para estimular a comunidade em seu entorno, fornecendo suporte aos desenvolvedores e aos usuários e sendo, muitas vezes, os porta-vozes entre a comunidade e os gestores do ecossistema [Fontao et al. 2015]. A caracterização dos 8 participantes é apresentada na Tabela 4, contendo o tempo de atuação dos desenvolvedores com tecnologias móveis, o porte das empresas que atuam, sendo: Pequena (até 100 funcionários), Média (de 101 a 1.000 funcionários) ou Grande (mais de 1.000 funcionários). Por fim, a tabela traz ainda em quais ecossistemas os participantes contribuíram durante as suas experiências com ECOS móvel. Vale salientar que, atualmente, os ecossistemas nos quais os evangelistas trabalham são Android ou iOS. Os demais são "residuais", ou seja, experiências anteriores dos evangelistas ou, no caso do Ev1, uma pessoa que atuou como evangelista por um determinado período.

Antes da realização deste estudo com os evangelistas, executou-se um piloto para resguardar a validade das questões apresentadas no script, sendo respondidas por dois pesquisadores associados aos grupos de pesquisa do primeiro e segundo autores, sendo que não necessariamente estes são especialistas no tópico de ecossistemas de software, mas sim sobre Engenharia de Software. Os feedbacks que estes pilotos geraram auxiliaram a aprimorar o script da entrevista.

Em seguida, enviou-se o convite para 20 evangelistas que foram selecionados por conveniência, ou seja, profissionais conhecidos pelos autores ou por seus grupos de pes-

iSys: Revista Brasileira de Sistemas de Informação (iSys: Brazilian Journal of Information Systems) http://seer.unirio.br/index.php/isys/ 
quisa para preencherem as entrevistas. Destes 20 convidados, 8 concordaram em participar das entrevistas. Desta forma, buscou-se coletar as suas opiniões sobre as possíveis forças, fraquezas, oportunidades e ameaças existentes em um ecossistema móvel.

A análise dos dados foi realizada por meio da metodologia de card sorting de acordo com as definições de Spencer [Spencer 2009], da mesma forma como ocorreu no estudo de campo anterior. Apesar dos novos dados trazerem insights bastante promissores, a quantidade de dados não foi extremamente extensa, permitindo que uma abordagem visual como a técnica de card sorting possa ser utilizada.

\section{Resultados}

Visando responder às questões de pesquisa, investigou-se os 12 fatores identificados no mapeamento sistemático da literatura, como eles são vistos pelos desenvolvedores e como estes fatores os influenciam a participarem e se manterem fiéis a um ECOS móvel.

\subsection{Fatores de Negócio na Literatura (QP1)}

Com base no processo apresentado na Seção 3.1, identificou-se os 12 fatores e suas descrições, conforme segue:

\section{(F1) Ganho financeiro e monetização dos aplicativos disponibilizados}

Definição: A remuneração pode ocorrer de duas formas, i.e., pela venda dos aplicativos ou pelo salário oferecido por alguma empresa que o desenvolvedor esteja vinculado. No primeiro caso, a forma de monetização dos aplicativos criadas pelos desenvolvedores deve ser flexível, apresentando mais de um modelo como opção ao desenvolvedor que permita a lucratividade [Deniz e Kehoe 2013, Fontao et al. 2017, Koch e Guceri-Ucar 2017, Koch e Kerschbaum 2014, Rieger e Majchrzak 2016, Sadi et al. 2015].

\section{(F2) Grande base instalada e participação dos usuários no mercado de aplicativos}

Definição: O tamanho da base instalada de um ECOS é relativo à quantidade de usuários, sendo que estes podem adquirir ou compram aplicativos ou serviços. Quanto maior a base instalada de um ECOS, bem como a participação dos usuários, mais possibilidades existem para promover as vendas dos aplicativos do desenvolvedor [Choi et al. 2017, Choi et al. 2018, Deniz e Kehoe 2013, Koch e Kerschbaum 2014, Sadi et al. 2015].

\section{(F3) Poucas barreiras impostas pelo mercado de aplicativos}

Definição: Todas as lojas da atualidade permitem fácil acesso ao mercado para desenvolvedores, minimizando as barreiras de entrada, fornecendo kits de desenvolvimento de software, suporte, licença de utilização e uma maneira eficiente de distribuição. Por poucas barreiras de entrada, tem-se baixa exigência monetária e de requisitos técnicos, por exemplo [Koch e Guceri-Ucar 2017, Koch e Kerschbaum 2014, Sadi et al. 2015].

\section{(F4) Participação e penetração no mercado de aplicativos}

Definição: Este fator se refere ao quanto um ECOS tem de penetração no mercado e possibilita assim a comercialização de aplicativos, levando o desenvolvedor a vislumbrar a sua venda [Deniz e Kehoe 2013, Koch e Kerschbaum 2014].

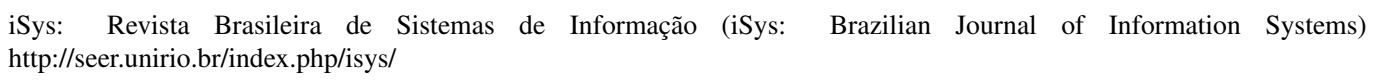




\section{(F5) Preço acessível dos dispositivos}

Definição: O preço razoável do dispositivo é importante não apenas para atrair usuários, que são os clientes destes ECOS, como também para o desenvolvedor que não precisa despender grande quantidade financeira para aquisição de um dispositivo para teste dos seus aplicativos, apoiando assim não apenas o teste, mas também todo o ciclo de desenvolvimento [Koch e Kerschbaum 2014].

\section{(F6) Canais de distribuição}

Definição: O desenvolvedor deve ter a liberdade para escolher quais dos canais disponíveis para distribuição de seus aplicativos. Além disso, estes canais escolhidos devem trazer renda ao desenvolvedor, além de reputação e oportunidades de carreira e aumento de seu portfólio. Estes canais devem ser simples em sua utilização para publicação destes aplicativos. Outro recurso desejável é distribuição em diversos locais do mundo, podendo, inclusive, delimitar regiões geográficas para disponibilidade [Deniz e Kehoe 2013, Koch e Kerschbaum 2014, Rieger e Majchrzak 2016].

\section{(F7) Variedade de fabricantes de dispositivos}

Definição: O ECOS tem abertura para possibilitar que diversos modelos de dispositivo possam ser comercializados com o sistema operacional deste ECOS. Da mesma forma, este sistema operacional deve se adequar facilmente a estes modelos de dispositivo. Quanto mais dispositivos utilizam o sistema, provavelmente maior alcance de usuários a aplicação do desenvolvedor terá [Choi et al. 2017, Choi et al. 2018, Dobrica e Pietraru 2017, Koch e Kerschbaum 2014].

\section{(F8) Oportunidades no mercado}

Definição: O mercado tem oportunidades e um crescente número de demandas dos usuários ou empresas, sendo que, quando o desenvolvedor disponibiliza uma aplicação que produziu, usuários ou empresas facilmente podem utilizá-la e este desenvolvedor tem uma oportunidade real de sua aplicação se tornar um destaque quanto à solução de determinada demanda dos usuários. O mercado apresenta demanda de trabalhos para compor serviços, o que pode atrair o desenvolvedor [Ryu et al. 2014].

\section{(F9) Credibilidade do ECOS com o compartilhamento em lucros}

Definição: Os proprietários do ECOS trabalham pelos interesses do desenvolvedor, não apenas para os seus próprios. Estes proprietários cumprem o contrato com os desenvolvedores, as políticas do ECOS são confiáveis e a forma como eles distribuem a receita pelas vendas com os desenvolvedores é atraente [Deniz e Kehoe 2013, Kim et al. 2016, Ryu et al. 2014].

\section{(F10) Consumo de aplicativos pelos usuários}

Definição: Os usuários buscam e utilizam serviços que os desenvolvedores disponibilizam na loja do ECOS. A demanda dos usuários é intensa, sendo que grande parte tem disposição para pagar por aplicativos que as atendam, ou assinar serviços periódicos para

\footnotetext{
iSys: Revista Brasileira de Sistemas de Informação (iSys: Brazilian Journal of Information Systems) http://seer.unirio.br/index.php/isys/
} 
Tabela 5. Opinião dos desenvolvedores quanto aos fatores identificados.

\begin{tabular}{|c|l|c|c|}
\hline ID & Fator & Começar & Permanecer \\
\hline F1 & $\begin{array}{l}\text { Ganho financeiro e monetização dos aplicativos } \\
\text { disponibilizados }\end{array}$ & 11 & 16 \\
\hline F2 & $\begin{array}{l}\text { Grande base instalada e participação dos usuários no } \\
\text { mercado de aplicativos }\end{array}$ & 12 & 12 \\
\hline F3 & $\begin{array}{l}\text { Poucas barreiras impostas pelo mercado de } \\
\text { aplicativos }\end{array}$ & 14 & 15 \\
\hline F4 & Participação e penetração no mercado de aplicativos & 12 & 13 \\
\hline F5 & Preço acessível dos dispositivos & 12 & 12 \\
\hline F6 & Canais de distribuição & 14 & 14 \\
\hline F7 & Variedade de fabricantes de dispositivos & 10 & 12 \\
\hline F8 & Oportunidades no mercado & 13 & 19 \\
\hline F9 & $\begin{array}{l}\text { Credibilidade do ECOS com o compartilhamento } \\
\text { em lucros }\end{array}$ & 9 & 12 \\
\hline F10 & Consumo de aplicativos pelos usuários & 15 & 17 \\
\hline F11 & Poucas chances de prejuízos monetários & 10 & 8 \\
\hline F12 & Apoio ao ciclo de vida dos aplicativos & 10 & 20 \\
\hline
\end{tabular}

tal [Deniz e Kehoe 2013, Kim et al. 2016].

\section{(F11) Poucas chances de prejuízos monetários}

Definição: Caso o desenvolvedor decida encerrar suas operações no ECOS, ele terá perdas triviais, podendo parar a qualquer momento. O desenvolvedor colabora enquanto sente que é mais lucrativo permanecer no ECOS do que se retirar dele [Kim et al. 2016].

\section{(F12) Apoio ao ciclo de vida dos aplicativos}

Definição: Refere-se ao quanto a plataforma suporta o ciclo de vida da aplicação. A plataforma deve auxiliá-lo no começo, durante a produção e após a distribuição de uma aplicação, ajudando na manutenção, com notificações e estatísticas ao desenvolvedor [Rieger e Majchrzak 2016].

\subsection{Fatores de Negócio e sua Influência sobre os Desenvolvedores (QP2)}

Os 12 fatores que foram identificados no mapeamento sistemático foram apresentados aos 20 desenvolvedores que participaram deste primeiro estudo de campo. Estes desenvolvedores foram convidados a responder se consideraram cada fator importante para começarem suas participações em um ECOS, ou para permanecerem participando. A Tabela 5 sumariza os fatores identificados pelo mapeamento e a quantidade de desenvolvedores que os apontaram como importantes para começar ou permanecer participando de um ECOS.

Após a apresentação dos fatores de negócio que podem influenciar um desenvolvedor, cada um dos participantes do primeiro estudo de campo foi convidado a discorrer sobre como esses fatores os impactaram a começarem ou permanecerem participando de

iSys: Revista Brasileira de Sistemas de Informação (iSys: Brazilian Journal of Information Systems) http://seer.unirio.br/index.php/isys/ 
um ECOS, conforme segue:

\section{(F1) Ganho financeiro e monetização dos aplicativos disponibilizados}

Os ganhos financeiros foram considerados importantes para começar por 11 desenvolvedores e para permanecer por 16 deles. O ganho financeiro muitas vezes estimula o desenvolvedor, fazendo com que o mesmo permaneça no ecossistema - "Muitas vezes, foi o que não me deixou desistir" (D3). Os ECOS possuem diversas formas de monetização e os desenvolvedores costumam apreciar essa flexibilidade - "Sempre foi importante a liberdade como o desenvolvedor quer ganhar dinheiro, se ele quiser fazer uma aplicação e ganhar dinheiro vendendo, ou fazendo um sistema de assinaturas, tudo bem, e se ele quer vender a força de trabalho dele para uma empresa, ótimo também” (D9). Atualmente, o que tem chamado mais a atenção dos desenvolvedores são as possibilidades de bons salários, para produção de aplicativos móveis para empresas - "A gente desenvolve software para poder gerar o salário que vai pagar as contas, então se você trabalha com isso, você tem que ter algum retorno financeiro em cima disso" (D6). Além disso, quando o desenvolvedor possui algum projeto no qual acredita, torna-se importante ganho financeiro para a manutenção do projeto, pois isso faz com que o desenvolvedor possa se sustentar enquanto se dedica a elaborar essa solução - "Para ti sustentar qualquer aplicação, ela precisa te dar dinheiro, se você fizer um produto que não tem um viés financeiro, (...), pelo menos vai ter que ganhar dinheiro no futuro, mesmo que você use isso como porta de entrada para outro projeto" (D10).

\section{(F2) Grande base instalada e participação dos usuários no mercado de aplicativos}

Uma grande base instalada é considerada importante tanto para começar quanto para continuar participando por 12 dos respondentes. Nem todo desenvolvedor busca uma grande base instalada, pois alguns projetos possuem público alvo definido, tornando desnecessário um grande público - "Não é importante porque eu já trabalhei em projetos de modelos de negócios que tinha poucos usuários, restritos" (D2). Contudo, os desenvolvedores salientam que o número de usuários simplesmente não significa sucesso, mas que desejam o máximo de clientes possível, pois estes investem em suas soluções de software - "Sempre que eu comecei algo novo foi importante a grande base de usuários, pois quanto mais usuários, mais pessoas vão utilizar tua aplicação e mais chances se tem de investimentos" (D3).

\section{(F3) Poucas barreiras impostas pelo mercado de aplicativos}

As poucas barreiras foram consideradas importantes por 14 desenvolvedores para começar e por 15 para continuarem participando de um ECOS móvel. Na verdade, barreiras altas desestimulam os desenvolvedores a participarem de um ecossistema - "Reduzir barreiras é muito importante porque estimula que mais desenvolvedores entrem no mundo das tecnologias móveis” (D9). Atualmente as barreiras dependem do ecossistema e suas regras, contudo, os ecossistemas consolidados possuem poucas barreiras, ou pelo menos barreiras com as quais os desenvolvedores conseguem lidar - "A gente sempre tem outras maneiras de fazer isso, mesmo que se tenha alguma barreira, você pode, por exemplo, recorrer a ferramentas open-source" (D8). Porém, alguns ecossistemas possuem barreiras

\footnotetext{
iSys: Revista Brasileira de Sistemas de Informação (iSys: Brazilian Journal of Information Systems) http://seer.unirio.br/index.php/isys/
} 
maiores que outros para os desenvolvedores - "No caso do iOS não é verdade, mas se tivesse potencializaria o desenvolvimento de aplicativos" (D17). Essas barreiras precisam existir, pois costumam garantir a qualidade dos aplicativos, cobrando níveis maiores dos desenvolvedores - "Pois com o passar do tempo notei que, isso aumentava a qualidade dos aplicativos que estão na loja” (D11).

\section{(F4) Participação e penetração no mercado de aplicativos}

A participação e penetração no mercado de aplicativos é considerado importante por 12 respondentes para começar e 13 para continuarem a desenvolver em um ECOS móvel. Em alguns casos, os desenvolvedores de projetos fechados não percebem essa participação, pois não são esses desenvolvedores que lidam diretamente com o mercado - "Eu não vivenciei isso, porque a gente desenvolvia muito específico para determinado cliente" (D7). Principalmente quando o desenvolvedor tem mais autonomia sobre sua aplicação, o desenvolvedor costuma desejar atingir o máximo de usuários, aumentando assim sua penetração no mercado - "a quantidade de clientes que você precisa para a sua aplicação é importante para fazer seu nome e fazer renda também" (D15). Além disso, hoje os desenvolvedores costumam participar de ambos ECOS líderes de mercado, sendo esses Android e iOS - "Agora o mercado acabou se padronizando em dois ecossistemas" (D12).

\section{(F5) Preço acessível dos dispositivos}

O preço acessível dos dispositivos é considerado importante tanto para começar quanto para continuar por 12 respondentes. Pela perspectiva do desenvolvedor, um dispositivo de preço mais acessível os auxilia quanto ao teste dos aplicativos, fazendo-os alcançar maior qualidade - "Eu tenho mais de um dispositivo de teste. Se esse hardware fosse muito caro, eu não tenho como ter esse hardware" (D4). Na perspectiva do usuário, quanto mais acessível um dispositivo, mais clientes em potencial o ecossistema atrai, pois podem adquiri-los mais facilmente - "Com dispositivos acessíveis você tem uma base maior de usuários e isso acaba fazendo com que você tenha mais clientes” (D17).

\section{(F6) Canais de distribuição}

Os canais de distribuição são considerados importantes por 14 desenvolvedores tanto para iniciar quanto para continuarem desenvolvendo no ecossistema. Apesar dos ECOS terem meios oficiais para distribuição, o desenvolvedor pode distribuir seus aplicativos em diversas formas, o que para alguns pode ser um atrativo - "É fácil você distribuir para os teus clientes, você pode fazer do jeito que quiser, você cria a sua loja se quiser" (D3). Contudo, alguns desenvolvedores preferem a loja oficial, pois é de onde costuma vir a maior renda - "Sempre gostei da informação estar concentrada em um lugar só quando o caso é a venda do produto" (D9).

Além disso, alguns desenvolvedores não distribuem seus aplicativos, sendo distribuídas por uma equipe de vendas de sua empresa - "Nós não éramos responsáveis pela distribuição" (D2). Por sua vez, mesmo não sendo sua responsabilidade em alguns casos, o conteúdo dos aplicativos devem respeitar a cultura de onde são distribuídos para não ferirem questões legais - "É muito diferente, por exemplo, você fazer uma distribuição no Brasil ou na China” (D12).

\footnotetext{
iSys: Revista Brasileira de Sistemas de Informação (iSys: Brazilian Journal of Information Systems) http://seer.unirio.br/index.php/isys/
} 


\section{(F7) Variedade de fabricantes de dispositivos}

Considerado importante para 10 desenvolvedores para começar e 12 para continuarem participando, pois geralmente um desenvolvedor busca atingir um determinado públicoalvo, o que faz este fator ser considerado um pouco menos importante - "Você tem um público-alvo que vai usar determinados dispositivos, então tem que desenvolver pensando nesses dispositivos" (D2). Contudo, alguns desenvolvedores desejam alcançar o máximo de usuários possível, buscando atingir mais clientes - "Os usuários tendo o acesso você vai ter com certeza uma maior quantidade de clientes e você vai ter provavelmente mais lucro (D5).

\section{(F8) Oportunidades no mercado}

As oportunidades de mercado são consideradas importantes por 13 desenvolvedores para começar e 19 para continuarem desenvolvendo no ecossistema. No mercado de aplicativos móveis, os desenvolvedores possuem muitas oportunidades e se destacam a cada aplicação bem sucedida - "Tem muita vaga aberta, tem muita oportunidade no mercado de tecnologias móveis, e até hoje não conseguiram suprir a demanda” (D2). Além disso, os desenvolvedores percebem no mercado a possibilidade de diferenciaçãopela venda de seus aplicativos, fazendo com que alguns obtenham sucesso - "Antes era menor porque tinha menos usuários, hoje a gente tem mais oportunidades, mas também tem muita aplicação que você pensa, tem uma ideia boa, vai desenvolver e já tem um em quatro línguas, então isso acontece muito, a gente tem que estar atento" (D7).

\section{(F9) Credibilidade do ECOS com o compartilhamento em lucros}

Este fator referente à relação entre ECOS e desenvolvedores é considerado importante para 9 para começarem e para 12 para continuarem desenvolvendo no ecossistema. Os desenvolvedores consideram que os ECOS móvel atuais são justos e isso leva a esses ecossistemas sobreviverem, fazendo com não se preocupem tanto com isso - "Certamente as regras de compartilhamento de lucros, sempre foram claras, e eu acho que sempre foram benéficas aos desenvolvedores" (D1). Para os desenvolvedores em geral, existem aqueles que não lidam com os lucros diretamente, pois quem lida com o lucro são outros membros de suas empresas - "No contexto que eu estava trabalhando eu não tinha acesso a essa parte” (D12). Contudo, para o ECOS é vantajoso apresentar credibilidade aos desenvolvedores, tornando-os mais próximos - "É muito mais satisfatório você desenvolver algo $\overline{q u e ~ v o c} \hat{e}$ faz parte (ecossistema)” (D17).

\section{(F10) Consumo de aplicativos pelos usuários}

Consumo de aplicativos é importante para 15 desenvolvedores para começar e 17 para continuar participando de um ECOS móvel. Quando o serviço é relevante aos usuários, os desenvolvedores podem decidir monetizar sobre esse aplicativo, podendo lucrar desta forma - "Se não tiver usuários utilizando e pagando por esse serviço, provavelmente o desenvolvedor não vai conseguir se sustentar na área" (D3). Na realidade, um desenvolvedor deseja atender as demandas dos usuários e mantém o seu foco nisto - "Se vocêe elabora um serviço bem feito, e ele resolve os problemas (do usuário), nada mais justo do que você cobrar e dar suporte para os usuários continuarem tendo esses serviços" (D9).

iSys: Revista Brasileira de Sistemas de Informação (iSys: Brazilian Journal of Information Systems) http://seer.unirio.br/index.php/isys/ 


\section{(F11) Poucas chances de prejuízos monetários}

É um fator que perdeu importância, de 10 para 8 desenvolvedores, pois caso o risco fosse alto, desmotivaria o desenvolvedor. Contudo, não é um risco atual - "Atualmente são poucas chances, mas no início o prejuízo era muito grande, se eu decidisse parar de desenvolver" (D7). Obviamente, um desenvolvedor não quer ter prejuízos e não se sentiria confortável caso fosse alto - "No início, eu me sentia arriscando em gastar com equipamento, licença, curso, mas hoje em dia eu não tenho esse pensamento de prejuízo, até porque todo conhecimento que eu já adquiri com certeza já pagou meus equipamentos, eu não olho muito para o fator financeiro nesses momentos" (D19).

\section{(F12) Apoio ao ciclo de vida dos aplicativos}

O apoio ao ciclo de vida dos aplicativos é considerado importante por metade dos entrevistado para começar e por todos para continuar participando de um ecossistema. Isso pois, inicialmente, muitos desenvolvedores desconhecem esses recursos e aprendem posteriormente - "No início eu não me importava tanto com isso, com estatística, com quem e quantas pessoas estavam baixando, porque eu não sabia, eu não tinha esse conhecimento, eu não sabia se isso era importante" (D16). Atualmente, os desenvolvedores percebem a importância deste suporte por meio de sua experiência - "Você potencializa que a sua aplicação sobreviva mais tempo, e com ela sobrevivendo mais tempo você tem mais sucesso" (D17). Além disso, este apoio auxilia os desenvolvedores a aprimorarem seus aplicativos, ou fazer manutenções quando necessário - "Você tem acesso de informações

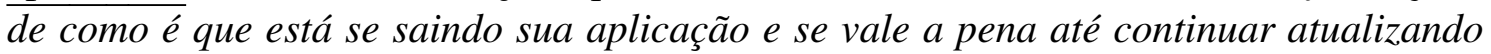
ela, fazendo manutenção" (D5).

\subsection{Forças, Fraquezas, Oportunidades e Ameaças na Dimensão de Negócios (QP3)}

A partir dos fatores identificados nos dois primeiros estudos, solicitou-se a 8 evangelistas entrevistados no novo estudo de campo que avaliassem a importância que cada fator possui para a carreira dos desenvolvedores, cuja ordem de importância está na Tabela 6. Assim sendo, fatores como Oportunidades de mercado (F8), Consumo de aplicativos pelos usuários (F10), Ganho financeiro e monetização dos aplicativos disponibilizados (F1) e Grande base instalada e participação dos usuários no mercado de aplicativos (F2) são considerados os fatores mais importantes considerados pelos evangelistas. Por outro lado, Preço acessível dos dispositivos (F5), Canais de distribuição (F6) e Variedade de fabricantes de dispositivos (F7) são aqueles menos importantes para a carreira dos desenvolvedores em um ECOS móvel na perspectiva dos entrevistados.

Em seguida, solicitou-se que os evangelistas pontuassem, a partir dos resultados provenientes do estudo de campo anterior, quais fatores podem representar alguma força, fraqueza, oportunidade ou ameaça ao desenvolvedor de um ECOS móvel, na dimensão de negócio. Os participantes sinalizaram, respectivamente, os fatores dispostos na Tabela 7.

Como forças em um ECOS, os evangelistas consideraram que, principalmente, os Ganho financeiro e monetização dos aplicativos disponibilizados (F1) e Oportunidades no mercado (F8) foram os fatores considerados como as maiores forças para os desenvolvedores destes ecossistemas. Nenhum fator foi considerado por eles como uma grande fraqueza para um ECOS móvel.

\footnotetext{
iSys: Revista Brasileira de Sistemas de Informação (iSys: Brazilian Journal of Information Systems) http://seer.unirio.br/index.php/isys/
} 
Tabela 6. Importância de cada fator para a carreira de um desenvolvedor na visão dos evangelistas.

\begin{tabular}{|l|c|c|c|c|c|}
\hline Fator & $\begin{array}{c}\text { Muito } \\
\text { Importante }\end{array}$ & Importante & Moderado & $\begin{array}{c}\text { Às Vezes é } \\
\text { Importante }\end{array}$ & $\begin{array}{c}\text { Não é } \\
\text { Importante }\end{array}$ \\
\hline (F1) & 4 & 4 & 0 & 0 & 0 \\
\hline (F2) & 4 & 3 & 1 & 0 & 0 \\
\hline (F3) & 1 & 5 & 2 & 0 & 0 \\
\hline (F4) & 3 & 4 & 0 & 1 & 0 \\
\hline (F5) & 2 & 1 & 1 & 3 & 1 \\
\hline (F6) & 2 & 2 & 2 & 1 & 1 \\
\hline (F7) & 2 & 1 & 0 & 4 & 1 \\
\hline (F8) & 6 & 2 & 0 & 0 & 0 \\
\hline (F9) & 3 & 2 & 2 & 1 & 0 \\
\hline (F10) & 5 & 3 & 0 & 0 & 0 \\
\hline (F11) & 1 & 4 & 2 & 1 & 0 \\
\hline (F12) & 3 & 3 & 2 & 0 & 0 \\
\hline
\end{tabular}

Os fatores que são mais considerados como oportunidades para os desenvolvedores presentes em um ECOS, como a Participação e penetração no mercado de aplicativos (F4) e o Consumo de aplicativos pelos usuários (F10). Como as maiores ameaças, os evangelistas consideraram principalmente o Preço acessível dos dispositivos (F5), Canais de distribuição (F6) e Variedade de fabricantes de dispositivos (F7).

Além disso, questionou-se os evangelistas quais as maiores forças, fraquezas, oportunidades ou ameaças presentes nos ECOS móvel quanto à dimensão de negócios para os desenvolvedores. As maiores forças destacadas pelos evangelistas (Tabela 8) são o fato de os ECOS móvel possuírem: (i) uma quantidade massiva de dispositivos e usuários, (ii) facilidade do uso dos dispositivos, (iii) pluralidade da oferta de dispositivos e que podem atingir diferentes tipos de orçamentos dos usuários, (iv) o possível retorno financeiro que os desenvolvedores podem atingir, (v) a possibilidade da realização de um roadmap do plano de negócio de aplicativos por meio dos recursos disponibilizados pelas lojas, (vi) a portabilidade das funcionalidade que antes eram realizadas pelo computador, também conhecida como responsividade, (vii) a possibilidade de escalar facilmente as soluções em um ecossistema, (viii) a possibilidade de canais oficiais de contato ou comunicação entre desenvolvedores e usuários da comunidade e (ix) o desenvolvedor por optar pela tecnologia que gostaria de desenvolver, podendo ser nativa nas tecnologias móveis ou uma tecnologia web com responsividade.

Entre as fraquezas apontadas pelos evangelistas (Tabela 9), estão: (i) o fato dos desenvolvedores terem um vasto conhecimento técnico mas, muitas vezes, se limitarem às questões técnicas e não pensarem ou investigarem a respeito das questões de negócio, (ii) a dificuldade do desenvolvedor se destacar a partir da produção de aplicativos, uma vez que a oferta de aplicativos costuma ser vasta em diversos nichos, (iii) o fato de não explorar corretamente o público alvo e consequentemente falhar na sua identificação, (iv) o preço dos dispositivos com recursos melhores ser mais elevado, dificultando o acesso

iSys: Revista Brasileira de Sistemas de Informação (iSys: Brazilian Journal of Information Systems) http://seer.unirio.br/index.php/isys/ 
Tabela 7. Forças, fraquezas, oportunidades e ameaças nos fatores de negócio identificados no primeiro estudo de campo.

\begin{tabular}{|c|c|}
\hline Forças & Fraquezas \\
\hline $\begin{array}{l}\text { (F1) Ganho financeiro e monetização } \\
\text { dos aplicativos disponibilizados; } \\
\text { (F8) Oportunidades no mercado; } \\
\text { (F2) Grande base instalada e } \\
\text { participação dos usuários no mercado } \\
\text { de aplicativos; } \\
\text { (F9) Credibilidade do ECOS com o } \\
\text { compartilhamento em lucros; e } \\
\text { (F11) Poucas chances de prejuízos } \\
\text { monetários. }\end{array}$ & - \\
\hline Oportunidades & Ameaças \\
\hline $\begin{array}{l}\text { (F4) Participação e penetração no } \\
\text { mercado de aplicativos; } \\
\text { (F10) Consumo de aplicativos pelos } \\
\text { usuários; } \\
\text { (F1) Ganho financeiro e monetização } \\
\text { dos aplicativos disponibilizados; } \\
\text { (F2) Grande base instalada e } \\
\text { participação dos usuários no mercado } \\
\text { de aplicativos; } \\
\text { (F3) Poucas barreiras impostas pelo } \\
\text { mercado de aplicativos; } \\
\text { (F12) Apoio ao ciclo de vida dos } \\
\text { aplicativos; } \\
\text { (F9) Credibilidade do ECOS com o } \\
\text { compartilhamento em lucros; e } \\
\text { (F11) Poucas chances de prejuízos } \\
\text { monetários. }\end{array}$ & $\begin{array}{l}\text { (F5) Preço acessível dos dispositivos; } \\
\text { (F6) Canais de distribuição; e } \\
\text { (F7) Variedade de fabricantes de } \\
\text { dispositivos }\end{array}$ \\
\hline
\end{tabular}

Tabela 8. Forças presentes na dimensão de negócios quanto à participação dos desenvolvedores em ECOS móvel.

Uso massivo de dispositivos pelas pessoas

Facilidade de uso

Pluralidade dos dispositivos

Retorno financeiro

Roadmap do plano de negócios

Portabilidade das funcionalidades

Escalabilidade das soluções do ECOS

Contato entre desenvolvedores e usuários

Poder optar entre desenvolver nativo ou responsivo

iSys: Revista Brasileira de Sistemas de Informação (iSys: Brazilian Journal of Information Systems) http://seer.unirio.br/index.php/isys/ 
Tabela 9. Fraquezas presentes na dimensão de negócios quanto à participação dos desenvolvedores em ECOS móvel.

Desenvolvedores se limitarem a questões técnicas e não pensarem em questões de negócio

Dificuldade de se destacar com aplicativos, pois já existem muitos à disposição

Errar o público alvo

Preço de dispositivos com melhores recursos serem mais elevados

Segurança da informação

\author{
Tabela 10. Oportunidades presentes na dimensão de negócios quanto à \\ participação dos desenvolvedores em ECOS móvel. \\ Desenvolvedor atingir seu público \\ Variedade de dispositivos \\ Diversidade de conteúdos técnicos \\ Criação de valores para comunidade \\ Escalabilidade \\ Aumento da produtividade \\ Crescimento do mercado de aplicativos \\ Senso de inovação dos desenvolvedores
}

a algumas aplicações que demandam recursos superiores para funcionarem em melhor desempenho e (v) a segurança da informação nos aplicativos desenvolvidos.

As oportunidades identificadas pelos evangelistas (Tabela 10) são: (i) a possibilidade de um desenvolvedor alcançar o seu público alvo por meio dos mecanismos do ecossistema, (ii) a variedade de dispositivos, pois, assim, atinge-se pessoas de todas as faixas monetárias, (iii) a diversidade de conteúdos técnicos sendo disponibilizados para a comunidade de desenvolvedores, (iv) a criação de aplicativos que gerem valor a uma comunidade, (v) a escalabilidade que o ecossistema apresenta, (vi) a possibilidade de produzir mais, (vii) a crescente demanda e mercado de aplicativos e (viii) o senso de inovação que é demandado para que os desenvolvedores possam se destacar.

Por fim, as ameaças identificadas pelos evangelistas (Tabela 11) são: (i) a necessidade de investimento pesado em marketing que é demandado aos desenvolvedores que gostariam de se destacar no mercado de aplicativos, (ii) a dificuldade do desenvolvedor encontrar suporte para alguns tipos de tecnologias, (iii) a falta de apoio com conteúdos técnicos especializados, além dos triviais oferecidos, (iv) a falta de visão de negócio por parte dos desenvolvedores, (v) a descontinuidade ou mudanças no sistema operacional, (vi) a falta de suporte e escalabilidade de atendimento do ecossistema ao desenvolvedor, (vii) a possível falta de interação com os usuários e (viii) a hipersaturação de ofertas de aplicativos dos mais diversos nichos no ecossistema.

Assim sendo, além dos fatores de negócios identificados anteriormente, os evangelistas apresentam pontos importantes a serem considerados quanto à dimensão de negócio para que os desenvolvedores possam refletir sobre suas contribuições e decidir de que formas podem realizar suas interações para manter uma boa relação com o seu ECOS. Os ECOS atualmente possuem mecanismos para lidar com este relacionamento com os de-

iSys: Revista Brasileira de Sistemas de Informação (iSys: Brazilian Journal of Information Systems) http://seer.unirio.br/index.php/isys/ 


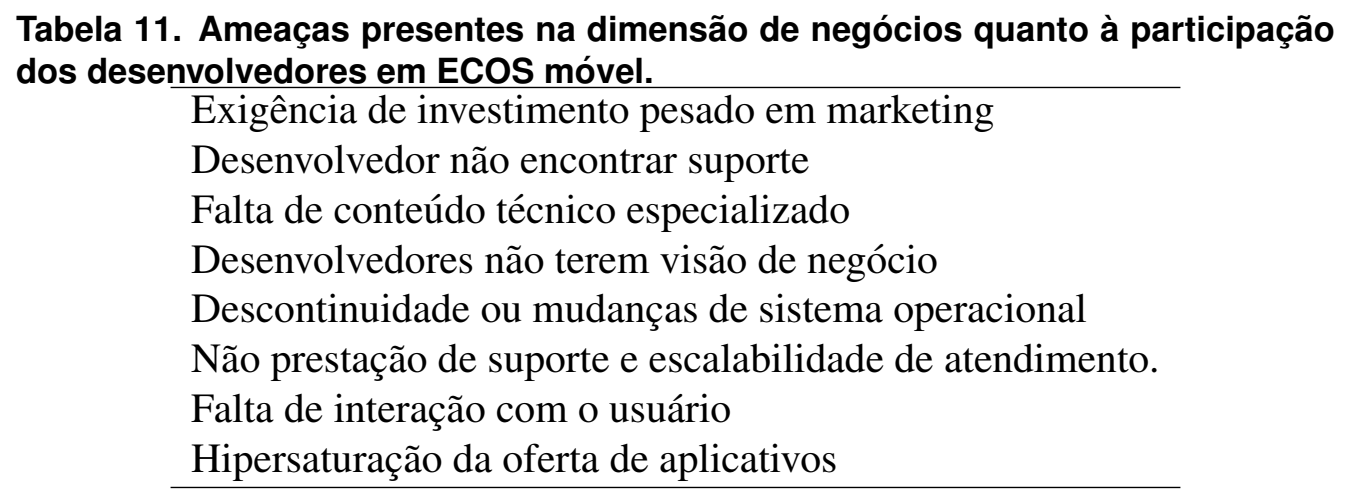

senvolvedores, em geral promovido por evangelistas, chamado de "Developer Relations (DevRel)", conforme apresentado no estudo de Fontão et al. [Fontão et al. 2020].

\section{Discussão}

Esta seção apresenta a discussão dos resultados obtidos e apresentados na Seção 4. A partir das respostas dos 20 desenvolvedores entrevistados, foram considerados mais importantes por 2 a cada 3 desenvolvedores os seguintes fatores: (F10) Consumo de aplicativos pelos usuários, (F3) Poucas barreiras impostas pelo mercado de aplicativos, (F6) Canais de distribuição e (F8) Oportunidades no mercado.

Inicialmente, foi identificado que um desenvolvedor costuma buscar um ECOS móvel que tenha um grande consumo de aplicativos (F10), onde existam grandes oportunidades de mercado (F8), os aplicativos podem ser distribuídos da forma que o desenvolvedor desejar (F6) e as barreiras para se ingressar nesse mercado de aplicativos sejam poucas (F3). Contudo, o desenvolvedor iniciante não tem uma visão completa sobre seu ECOS ou sobre a sua participação.

Da mesma forma, os desenvolvedores, para continuarem participando, pontuam como mais importante: (F12) Apoio ao ciclo de vida dos aplicativos, (F8) Oportunidades no mercado, (F10) Consumo de aplicativos pelos usuários, (F1) Ganho financeiro e monetização dos aplicativos disponibilizados, (F3) Poucas barreiras pelo mercado de aplicativos, (F6) Canais de distribuição e (F4) Participação e penetração no mercado de aplicativos.

Após um tempo participando de um ECOS, foi identificado que, além dos fatores que os desenvolvedores consideravam importante ao iniciar, surgem novos fatores bem considerados, como: (F12) Apoio ao ciclo de vida dos aplicativos, que percebem isso apenas após a produção de alguns aplicativos, e (F1) Ganho financeiro e monetização dos aplicativos disponibilizados, pois percebem que trabalhar com tecnologias móveis aumenta oportunidades de trabalhar em empresas ou cargos melhores. Além disso, percebem que seus aplicativos podem ter penetração no mercado de aplicativos (F4).

Os fatores que ganham mais importância ao longo do tempo são: (F12) Apoio ao ciclo de vida dos aplicativos; (F8) Oportunidades no mercado, que se torna ainda mais importante; (F1) Ganho financeiro e monetização dos aplicativos disponibilizados e (F9) Credibilidade do ECOS com o compartilhamento em lucros. Estes fatores não

iSys: Revista Brasileira de Sistemas de Informação (iSys: Brazilian Journal of Information Systems) http://seer.unirio.br/index.php/isys/ 
necessariamente são em algum momento reconhecidos como importantes, mas tiveram a maior variação de importância considerada pelos desenvolvedores entrevistados. Além disso, (F11) Poucas chances de prejuízos monetários perdeu importância de acordo com os desenvolvedores. Conforme apresentado na Seção 4, muitos desenvolvedores apontam que inicialmente poderiam ter sentido este receio, mas que atualmente são poucas as chances de um prejuízo real.

Por outro lado, três fatores seguiram estáveis pela análise dos 20 desenvolvedores (mesma importância tanto para começar como para continuar participando de um ECOS): (F6) Canais de distribuição, que foi apontado como um dos fatores mais importantes, e (F2) Grande base instalada e participação dos usuários no mercado de aplicativos e (F5) Preço acessível dos dispositivos, que foram considerados um pouco menos importantes.

Desta forma, os fatores de negócio exercem influência considerável no desenvolvedor, por envolverem aspectos de remuneração pessoal e vendas de seus aplicativos. Contudo, os desenvolvedores estão tendo menos receio de se arriscar, uma vez que o mercado de produção de aplicativos está em ascensão. Além disso, o trabalho em contextos empresariais se torna bastante atrativo, apesar de muitos desenvolvedores participarem de projetos por outras razões que não apenas a lucratividade.

No segundo estudo de campo, buscou-se, por meio dos profissionais que possuem uma visão mais abrangente da comunidade de desenvolvedores, a identificação das forças, fraquezas, oportunidades e ameaças que estão presentes em um ECOS móvel. Os ecossistemas têm grande forças como: (i) o grande alcance de usuários e a disponibilidade de diversos modelos de dispositivos que podem ser utilizados como oportunidades pelos desenvolvedores, (ii) podendo assim atingir uma quantidade maior de potenciais clientes, (iii) ter uma atenção maior por parte do ecossistema quanto ao acesso de material técnico, (iv) desenvolver, junto com o ecossistema e com os usuários, aplicativos com valor e (v) apesar de competitivo, costuma ser receptivo a inovações quando vão de encontro ao esperado pela comunidade de usuários.

Da mesma forma, algumas fraquezas podem representar ameaças aos desenvolvedores na visão dos evangelistas em especial, pois os desenvolvedores costumam não ter experiência ou o devido cuidado com as questões de negócio, sobretudo no início de suas relações com um ecossistema, podendo assim: (i) errar o público alvo, (ii) desenvolver aplicativos que não atingem demandas reais dos usuários, (iii) ter dependência de conhecimentos para além dos tecnológicos, (iv) demandar o entendimento do modelo de negócio do ecossistema e de sua aplicação, (v) desenvolver um roadmap deste modelo para sua aplicação atingir seus objetivos e (vi) conseguir contar com profissionais que entendam de marketing ou com outros colegas que lhe forneçam materiais mais especializados, ou algum tipo de suporte tanto em questões de negócio como em questões técnicas avançadas (e.g., sobre a segurança de informação nos aplicativos - um desafio nada trivial).

\section{Limitações}

Como todo estudo experimental, algumas limitações e dificuldades foram enfrentadas, como: i) a heterogeneidade dos entrevistados não foi muito alta, uma vez que os desenvolvedores convidados para as entrevistas são todos brasileiros, podendo desenvolvedores de

\footnotetext{
iSys: Revista Brasileira de Sistemas de Informação (iSys: Brazilian Journal of Information Systems) http://seer.unirio.br/index.php/isys/
} 
outras nacionalidades considerarem outros fatores mais ou menos importantes; ii) alguns desenvolvedores entrevistados podem ter concordado com a importância de alguns fatores que lhes foram apresentados, apesar de nunca tê-los considerado até o presente momento (sem reflexão sobre o impacto destes fatores em suas decisões antes); e iii) a opinião dos desenvolvedores ou dos evangelistas podem sofrer uma maturação com o passar do tempo e de suas experiências, fazendo com que mesmo o mais experiente dos desenvolvedores entrevistados possa, em algum momento, ter novas conclusões sobre estes fatores.

\section{Conclusão}

A partir desta pesquisa, foi possível constatar que os fatores de negócio podem implicar na decisão de um desenvolvedor para participar ou se manter participando de um ECOS móvel. Inicialmente, os desenvolvedores demonstram que conheciam menos fatores (ou os conheciam em menor profundidade). No entanto, ao longo do tempo, tornam-se mais exigentes pois sentem que, enquanto profissionais e entendedores da tecnologia, podem escolher mais livremente os seus passos em um ECOS móvel.

A partir desta pesquisa, buscou-se contribuir com o esclarecimento de algumas lacunas que foram identificadas na literatura como, por exemplo, o estudo de Souza et al. [de Souza et al. 2016] que apontam uma limitação nos estudos que retratam a perspectiva social (por exemplo, a motivação do desenvolvedor), podendo assim entender como a dimensão de negócio pode influenciar esses desenvolvedores. Além disso, este estudo pode auxiliar desenvolvedores novatos a escolherem um ECOS móvel, a partir do entendimento de quais fatores são importantes para os desenvolvedores que já participam há mais tempo, considerando ainda a perspectiva de evangelistas.

Esta pesquisa abre possibilidades para trabalhos futuros. Por exemplo, sugerese investigar em literatura correlata se existem outros fatores de negócio não apreciados neste estudo. Outra possibilidade é a realização de uma pesquisa de opinião em escala global visando generalizar os resultados.

\section{Agradecimentos}

Agradecemos ao CNPq (processos 420801/2016-2, 311256/2018-0 e 307177/20181) pelo apoio financeiro e a PUCRS pelo subsídio aos assistentes de pesquisa de graduação (Edital BPA-PRAIAS 2018 e 2019). Agradecemos ainda ao apoio financeiro da PROPESP/UFPA. Por fim, o segundo autor agradece a UNIRIO e FAPERJ (Proc. 211.583/2019).

\section{Referências}

Abdalla, A., Ströele, V., Campos, F., David, J. M. N., and Braga, R. (2018). Plataforma de ecossistema de software para sistemas de recomendação. In Simpósio Brasileiro de Sistemas de Inf., pages 559-551, Caxias do Sul, Brazil. SBC.

Boscarioli, C., Araujo, R. M., and Maciel, S. P., editors (2017). Grand Research Challenges in Information Systems in Brazil 2016 -2026. Brazilian Computer Society, Special Committee on Information Systems (CE-SI).

iSys: Revista Brasileira de Sistemas de Informação (iSys: Brazilian Journal of Information Systems) http://seer.unirio.br/index.php/isys/ 
Bosch, J. and Bosch-Sijtsema, P. (2010). From integration to composition: On the impact of software product lines, global development and ecosystems. Journal of Systems and Software, 83(1):67-76.

Campbell, P. and Ahmed, F. (2010). A three-dimensional view of software ecosystems. In Proceedings of the European Conference on Software Architecture: Companion Volume, pages 81-84, Copenhagen, Denmark. ACM.

Choi, G., Nam, C., and Kim, S. (2017). The impacts of mobile platform openness on application developers' intention to continuously use a platform: From an ecosystem perspective. In Proc. of the International Telecommunications Society, pages 1-28, Passau, Germany. econstor.

Choi, G., Nam, C., and Kim, S. (2018). The impacts of technology platform openness on application developers' intention to continuously use a platform: From an ecosystem perspective. Telecom. Policy, 42(1):1-14.

de Souza, C. R., Figueira Filho, F., Miranda, M., Ferreira, R. P., Treude, C., and Singer, L. (2016). The social side of software platform ecosystems. In Proceedings of the Conference on Human Factors in Computing Systems, pages 3204-3214, San Jose, California. ACM.

Deniz, S. and Kehoe, F. (2013). Fostering innovation: Factors that attract and retain third party developers in mobile ecosystems. Master thesis, Lund University.

Dhungana, D., Groher, I., Schludermann, E., and Biffl, S. (2010). Software ecosystems vs. natural ecosystems: learning from the ingenious mind of nature. In Proceedings of the European Conference on Software Architecture: Companion Volume, pages 96102, Copenhagen, Denmark. ACM.

Dobrica, L. and Pietraru, R. (2017). Experiencing native mobile health applications development. In Proceedings of the International Conference on Control Systems and Computer Science, pages 523-528, Bucharest, Romania. IEEE.

Ferreira, R. d. P. (2016). Um estudo exploratório dos fatores de adoção de plataformas de software móveis. Master thesis, UFPA, Brazil.

Fontão, A., Cleger-Tamayo, S., Wiese, I., Santos, R. P. d., and Dias-Neto, A. C. (2020). On value creation in developer relations (devrel) a practitioners' perspective. In International Conference on Global Software Engineering, pages 33-42, Seoul, South Korea.

Fontao, A. d. L., Dias-Neto, A., and Santos, R. (2017). Towards a guideline-based approach to govern developers in mobile software ecosystems. Mastering Scale and Complexity in Software Reuse, 10221(1):208-213.

Fontao, A. d. L., dos Santos, R. P., and Dias-Neto, A. C. (2015). Mobile software ecosystem (mseco): a systematic mapping study. In Proc. of the Computer Software and Applications Conf., pages 653-658, Taichung, Taiwan. IEEE.

Goldbach, T. and Benlian, A. (2015). Understanding informal control modes on software platforms-the mediating role of third-party developers' intrinsic motivation. In

iSys: Revista Brasileira de Sistemas de Informação (iSys: Brazilian Journal of Information Systems) http://seer.unirio.br/index.php/isys/ 
Proceedings of the International Conference on Information Systems, pages 1-20, Las Vegas, USA. aisel.

Goldbach, T., Benlian, A., and Buxmann, P. (2017). Differential effects of formal and self-control in mobile platform ecosystems: Multi-method findings on third-party developers' continuance intentions and application quality. Information \& Management, 55(3):271-284.

Kim, H. J., Kim, I., and Lee, H. (2016). Third-party mobile app developers' continued participation in platform-centric ecosystems: An empirical investigation of two different mechanisms. International Journal of Information Management, 36(1):44-59.

Kitchenham, B., Brereton, O. P., Budgen, D., Turner, M., Bailey, J., and Linkman, S. (2009). Systematic literature reviews in software engineering-a systematic literature review. Information and Software Technology, 51(1):7-15.

Koch, S. and Guceri-Ucar, G. (2017). Motivations of application developers: Innovation, business model choice, release policy, and success. Journal of Organizational Computing and Electronic Commerce, 27(1):218-238.

Koch, S. and Kerschbaum, M. (2014). Joining a smartphone ecosystem: Application developers' motivations and decision criteria. Information and Software Technology, 56(1):1423-1435.

Lima, T., Barbosa, G., dos Santos, R. P., and Werner, C. (2014). Uma abordagem sociotécnica para apoiar ecossistemas de software. iSys-Revista Brasileira de Sistemas de Informação, 7(3):19-37.

Mallinson, K. (2015). Smartphone revolution: Technology patenting and licensing fosters innovation, market entry, and exceptional growth. IEEE Consumer Electronics Magazine, 4(2):60-66.

Manikas, K. and Hansen, K. (2013). Software ecosystems - a systematic literature review. Journal of Systems and Software, 86(5):1294-1306.

Meireles, A. I., dos Santos, R. P., and Cappelli, C. (2019). Um instrumento para avaliação e sugestões de mecanismos de transparência em portais de ecossistemas de software. iSys-Brazilian Journal of Information Systems, 12(2):05-38.

Miranda, M., Ferreira, R., de Souza, C. R., Figueira Filho, F., and Singer, L. (2014). An exploratory study of the adoption of mobile development platforms by software engineers. In Proceedings of the International Conference on Mobile Software Engineering and Systems, pages 50-53, Hyderabad, India. ACM.

Petersen, K., Feldt, R., Mujtaba, S., and Mattsson, M. (2008). Systematic mapping studies in software engineering. In Evaluation and Assessment in Software Engineering, volume 8, pages 68-77, Bari, Italy. EASE.

Rieger, C. and Majchrzak, T. A. (2016). Weighted evaluation framework for crossplatform app development approaches. In Proceedings of the EuroSymposium on Systems Analysis and Design, pages 18-39, Gdansk, Poland. Springer.

iSys: Revista Brasileira de Sistemas de Informação (iSys: Brazilian Journal of Information Systems) http://seer.unirio.br/index.php/isys/ 
Ryu, M. H., Kim, J., and Kim, S. (2014). Factors affecting application developers' loyalty to mobile platforms. Computers in Human Behavior, 40(1):78-85.

Sadi, M. H., Dai, J., and Yu, E. (2015). Designing software ecosystems: How to develop sustainable collaborations? Advanced Information Systems Engineering Workshops, 215(1):161-173.

Santos, M., Fernandes, J., Villela, M., and Santos, R. (2019). Fatores de interação humano-computador em ecossistemas de software: Um mapeamento sistemático de literatura. In Anais do XV Simpósio Brasileiro de Sistemas de Informação, page 8, Aracaju, Brazil. SBC.

Santos, R. P. and Werner, C. M. L. (2011). A proposal for software ecosystems engineering. In Jansen, S., Bosch, J., Campbell, P. R. J., and Ahmed, F., editors, Proceedings of the Third International Workshop on Software Ecosystems, volume 746 of CEUR Workshop Proceedings, pages 40-51, Brussels, Belgium. CEUR-WS.org.

Singer, J., Sim, S. E., and Lethbridge, T. C. (2008). Software engineering data collection for field studies. In Shull, F., Singer, J., and Sjoberg, D. I., editors, Guide to Advanced Empirical Software Engineering, chapter 1, pages 9-34. Springer, London, UK.

Spencer, D. (2009). Card sorting: Designing usable categories. Rosenfeld Media, New York, USA.

Steglich, C., Marczak, S., De Souza, C. R., Guerra, L. P., Mosmann, L. H., Figueira Filho, F., and Perin, M. (2019a). Social aspects and how they influence mseco developers. In IEEE/ACM International Workshop on Cooperative and Human Aspects of Software Engineering, pages 99-106, Montreal, Canada. IEEE.

Steglich, C., Marczak, S., Santos, R., Guerra, L. P., Mosmann, L. H., de Souza, C., Figueira Filho, F., and Perin, M. (2019b). How do technical factors affect developers in mobile software ecosystems. In Workshop on Software Visualization, Evolution and Maintenance, pages 70-77, Salvador, Brazil. SBC.

Steglich, C., Marczak, S., Santos, R., Mosmann, L. H., Guerra, L. P., de Souza, C., Filho, F. F., and Perin, M. (2020). How do business factors affect developers in mobile software ecosystems? In Brazilian Symposium on Information Systems, pages 1-8, São Bernardo do Campo, Brazil.

Wohlin, C. (2014). Guidelines for snowballing in systematic literature studies and a replication in software engineering. In Proc. of the International Conference on Evaluation and Assessment in Software Engineering, page 38, London, UK. ACM.

iSys: Revista Brasileira de Sistemas de Informação (iSys: Brazilian Journal of Information Systems) http://seer.unirio.br/index.php/isys/ 